\title{
Research on Financial Audit Innovation Based on Blockchain Technology
}

\author{
Ming Wei ${ }^{a}$ and Rui Ding ${ }^{b}$ \\ School of Economics and Management, Xi'an University of Posts \& Telecommunications, Xi'an, \\ 710061 China

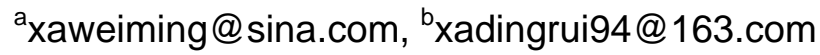

Keywords: blockchain technology, financial audit, warning mechanism, data storage

\begin{abstract}
The strategy of scientific and technological innovation put forward by the 18th and 19th National Congress of the Communist Party of China has provided a new direction for the development of various industries. The superiority of blockchain technology can just as a scientific and technological innovation to make up for deficiencies of financial audit in process and data storage. By analyzing the principles and characteristics of blockchain technology, we apply blockchain technology to the whole financial audit process and put forward the warning mechanism of financial audit implementation process so as to optimize the data storage and the process of financial audit.
\end{abstract}

\section{Introduction}

The 18th National Congress of the Communist Party of China ${ }^{[1]}$ held clearly pointed out that scientific and technological innovation is a strategic support for raising social productive forces and comprehensive national strength, and must be placed in the core position of the overall development of the country. In 2017, General Secretary Xi Jinping pointed out that innovation is the first impetus to development and a strategic support for building a modern economic system in the report to the 19th Congress ${ }^{[2]}$. The technological advantages and features of blockchain technology perfectly fit the strategic orientation. Therefore, it is of great significance to analyze the blockchain technology for the innovation of financial audit process.

\section{The Principle and Characteristics of Blockchain Technology}

\subsection{The Principle of Blockchain Technology}

Blockchain technology is a new application mode, which integrates distributed data storage, point to point transmission, consensus mechanism, encryption algorithm and other computer technology ${ }^{[3]}$. It is a chain data structure that is composed of chunks of data blocks combined in order by time sequence. At the same time, it is a distributed ledger that is cryptographically guaranteed the data not to be tampered or forged.

\subsection{The Characteristics of Blockchain Technology}

Blockchain technology has the following five advantages: (1) Decentralization. Each node in the blockchain is independent and self-managed, making the data distributed record, storage and update ${ }^{[4]}$. (2) Openness. There is a record of data and operations on the blockchain that can be reviewed, tracked and restored with high levels of transparency. (3) Autonomy. All nodes in the whole blockchain system can operate on the data freely and safely in a trusted environment and no human intervention can work. (4) Information is irreversible. Modifying a single node's data on the blockchain is not valid for the entire data in database changes unless it is possible to modify more than half of the nodes on the control blockchain at the same time ${ }^{[5]}$. (5) Anonymity. When data is exchanged or traded, it doesn't need to be verified, it can be carried out directly. 


\section{Problems Existing in Financial Audit}

\subsection{Storage Space and Time Range of Financial Audit Material are Limited}

At present, accounting information of enterprises in China is mainly recorded in the electronic accounting system and paper books. The electronic accounting system has limited storage space. The books, vouchers and the like in paper occupy a lot of physical space in the enterprise. Some accounting information will be destroyed regularly after 3 years or 5 years, which also limits the storage of accounting information in the enterprise over time. Therefore, the lack of information may affect the accuracy of financial audit.

\subsection{Coverage of Financial Audit is Not Wide Enough}

In the process of financial audit, the authenticity of the whole transaction data is not usually verified. It is also difficult to cover all the assets in the physical inventory. Instead, the statistical sampling method is adopted to control the audit cost and improve the audit efficiency. Auditors will only carry out detailed tests on key points or internal management control when they have doubts. The scope of financial audit evidence collection is too one-sided and may overlook some important audit doubt points.

\subsection{Data of the Audited Entity is Easy to be Tampered}

At present, most corporates' accountants use the electronic accounting system, but there are still some small enterprises in our country using manual accounting because of lack information technology. There is risk that accounting information can be easily tampered either way. As for electronic data, accountants can easily modify the data has been entered without leaving any trace, making it difficult for financial auditors to find fake electronic data.

\section{The Advantages of Blockchain Technology Applying in Financial Audit}

\subsection{Improve Financial Audit Data Recording and Storage}

The time stamp function in the blockchain technology can not only record the basic information such as quantity and amount of each transaction, but also record the update time of the data accordingly. Data are arranged in chronological order so that they can be tracked continuously and the efficiency of financial audit work will be improved. The decentralization of blockchain can improve storage mode. This distributed storage mechanism makes every node of the chain store the financial audit data and reduces the storage cost of financial audit data.

\subsection{Broaden the Scope of Financial Audit Supervision}

In the blockchain database, recording and updating every data will be synchronized to the entire blockchain, and the node with corresponding key has the right to query the data on the entire blockchain. At the same time, the distributed accounting function of the blockchain ensures the integrity of accounting information. The data on each block can be traced back to the auditors who own the authorized key and verified so that it can broaden the scope of financial audit supervision.

\subsection{Guarantee Financial Audit Data Integrity}

The data on the blockchain is irrevocable as soon as it is entered. The blockchain system will compare the new data with current books, and the same and duplicate data will be identified as real books. It would not be possible to tamper with a piece of data unless tampering with more than 51\% of the data on the chain at the same time. Because it will cost a huge amount of money and be released to every node on the blockchain. Auditors can access any of the blocks on the chain to obtain authentic and up-to-date financial audit data so as to improve financial audit productivity. 


\section{Financial Audit Innovation Based on Blockchain Technology}

Based on the characteristics of the blockchain technology, we apply the blockchain technology with the financial auditing to solve the problems in the current financial auditing in our country. On the one hand, blockchain technology can improve the storage of financial audit data. On the other hand, we can apply the blockchain technology to financial audit process, so that the situation of each phase can be feedback to the blockchain database of financial audit.

\subsection{Financial Audit Preparation Phase}

In this phase, the auditors must understand and collect the relevant information of the audited entity and upload the data to the financial audit blockchain database through technical means. Then they assess the audited entity's management system and internal control system, fully identify and assess the risk of material misstatement of financial statements, to determine the nature of the risk assessment process, timing and scope to be determined. Finally, they determine the level of materiality and audit risk, and preparing specific audit plan.

\subsection{Financial Audit Implementation Phase}

The financial audit implementation phase is the core of the entire audit process. Firstly, use blockchain timestamp technology to certify the ownership of all assets in the audited entity, such as tangible assets, intangible assets, securities, et al. Secondly, implement risk response procedures, including the overall response to the risk of material misstatement at the level of financial statements, further audit procedures for the identified risk of material misstatement, control testing and substantive procedures.

A warning mechanism is constructed during the specific financial implementation phase (shown as Fig.1). The first step is to confirm whether a piece of data in the blockchain database of the financial audit is normal or not. If it is normal, a new block is formed and uploaded to the blockchain. The system automatically acquiesces in the real books and records related information. If it is abnormal, the blockchain system will inform the auditors of data anomalies. The second step is the auditor to confirm whether the data is true. If it is true, follow the first step. If not, check whether the financial audit blockchain database can get more information. The third step is to check whether more financial audit data can be obtained. If you can obtain more financial audit data, get back to the auditor to confirm the data is true. If you can't get more financial audit information, it will be invalid business. The blockchain system acquiesces in fake accounts and feedback into the risk assessment process. The auditor needs to re-evaluate the risk. 


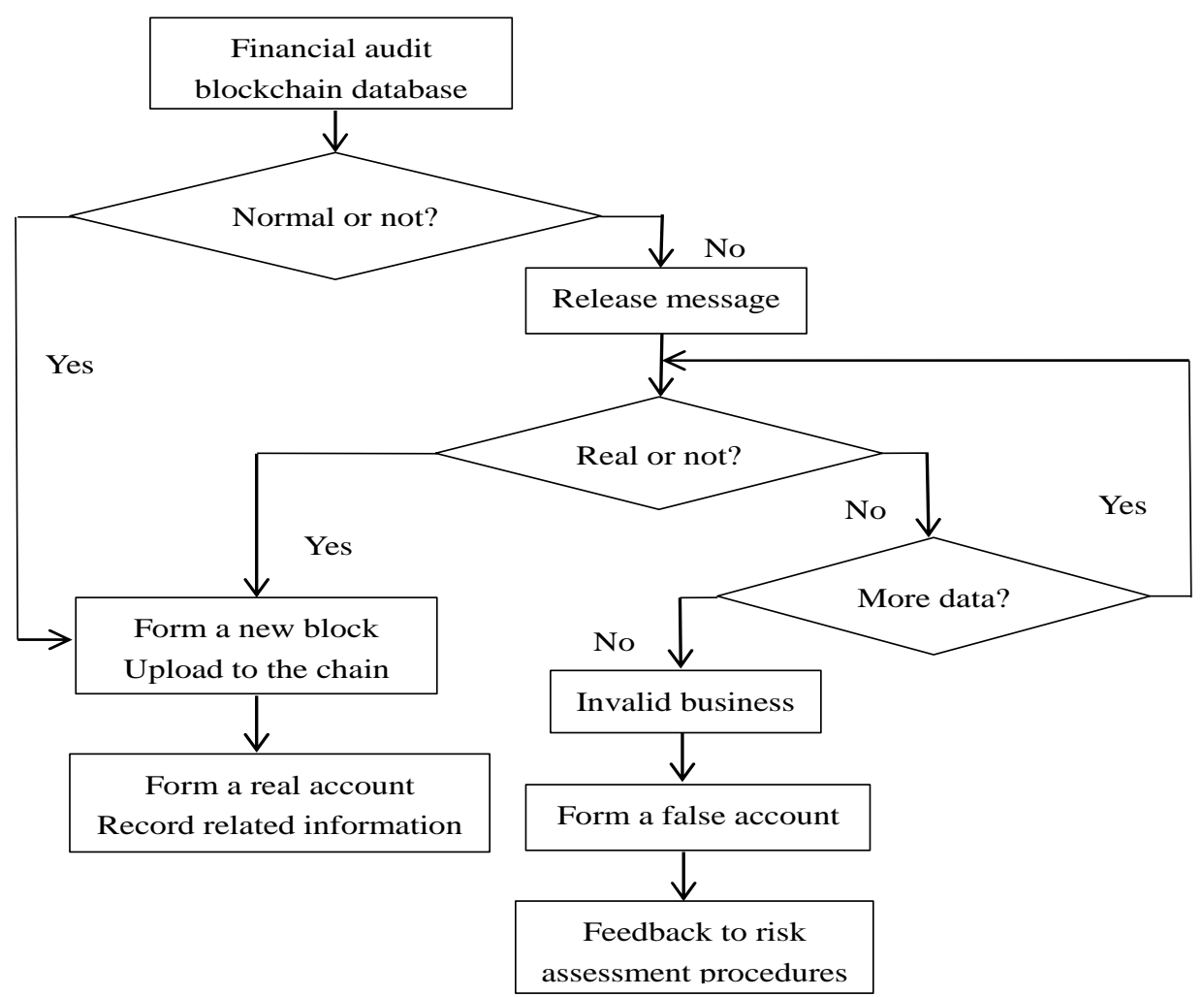

Fig.1. Financial audit warning mechanism based on blockchain technology

\subsection{Financial Audit Reporting Phase}

The content of the financial audit reporting stage based on blockchain technology is no different from the traditional audit reporting stage. It is necessary to conduct the collating and evaluating evidences of financial audit, composite financial audit work sheet, prepare financial audit reports, and prepare management proposals for financial audit results. Financial auditors should upload the financial audit data to the blockchain database, which is convenient for verification.

\subsection{Following-up Financial Audit Phase}

Following-up financial audit stage requires the audited entity based on the financial audit opinion for rectification, mainly in the following steps: (1) Financial auditors analyze the audited entity's audit description and response; (2) Draw up the follow-up financial audit program; (3) Auditors are on-site audit; (4) Evaluate the financial audit evidence; (5) Provide follow-up financial audit report and upload to blockchain.

\section{Conclusion}

In this paper, we discuss the circumstances of big data, Internet plus and the strategic policy of national science and technology innovation. Try to explore the application of blockchain technology as an innovation point to promote financial audit to develop the direction on informatization and high-tech. Apply the technical characteristics of blockchain technology to every stage of the financial audit process. Blockchain technology has a wide range of applications in the financial audit because of its superiority. The use of blockchain technology can not only expand the storage space of financial audit data, but also ensure the financial audit data cannot be tampered. What's more, it can improve the financial audit process, make the financial audit process more standardized and speed up the information construction of financial audit work. However, blockchain technology is still in its initial stage of development, and there is still less specific applications in the field of financial audit in China. Therefore, auditors should carefully choose the appropriate audit procedures and reduce the risk of financial audit. 


\section{Acknowledgement}

In this paper, the research was sponsored by Social Science Fund Project of Shaanxi Province (Project No. 2015D043); Research Project of National Audit Office of the People's Republic of China (Project No.17SJ01001) and Soft Science Research Project of Shaanxi Province (Project No.2016KRM036).

\section{References}

[1] Zhang Lizhen, Qin Zhilong. Research on Innovation Driven Development Strategy Since Eighteen: a Literature Review [J]. Journal of Sichuan University of Science and Engineering (Social Sciences Edition), 201530 (4): 83-90.

[2] Li Zhen. Innovation Driven: Leading the Development of the First Power [EB/OL]. (2017-10-21)[2017-11-26].

http://cpc.people.com.cn/19th/n1/2017/1021/c414305-29599871.html.

[3] Huang Guanhua. Blockchain Improve the Network Audit Approach [J] .Financial Science, 2016 (10): 84-91.

[4] Chen Fang. Financial Audit Based on Blockchain Analysis [J]. Accounting Learning, 2017(18): 145.

[5] Chen Xu, Ji Chenghao. Real-time Auditing Based on Blockchain Technology [J]. Journal of Certified Public Accountants, 2017 (4): 67-71. 